\title{
El extracto inédito de una carta de Jovellanos a Alexander Jardine (18 de octubre de 1794)
}

\author{
Elena de Lorenzo Álvarez \\ Instituto Feijoo de Estudios del Siglo XVIII (IFES.XVIII)
}

CES.XVIII, núm. 18 (2008), págs. 23-31. 
Resumen: Se edita el extracto autógrafo e inédito de una carta dirigida por Jovellanos a Alexander Jardine el 18 de octubre de 1794, depositado en el legado de Gómez de Arteche de la Biblioteca del Senado.

Palabras clave: Jovellanos. Epistolario. Alexander Jardine. 
En el legado de José Gómez de Arteche, depositado hoy en la Biblioteca del Senado, entre los papeles de Jovellanos catalogados como Varias hojas referentes al P. Eleta, Cabarrús, Abate Gándara, Pérez Bayer, Merlo, Huerta, Juan Orry, Miguel María de Nava, etc., se encuentran dos cuartillas manuscritas inéditas de Jovellanos en que extracta una carta dirigida un 18 de octubre «A Jardin», obviamente, el cónsul de Inglaterra en La Coruña, Alexander Jardine.

Que el extracto aparezca entre los papeles de Gómez de Arteche no es extraño y poco hay que explicar ya de la dispersión de los manuscritos de Jovellanos. El propio Arteche brindó a Julio Somoza copias de los manuscritos y Somoza afirma que los generales Evaristo Fernández San Miguel y José Gómez de Arteche compraron parte del fondo de Ceán Bermúdez a su viuda, Manuela Camos; en el Inventario detalla que Arteche los compró a los hijos de Evaristo San Miguel. Sin embargo, Somoza da cuenta en el Inventario de estas Varias hojas, anotando: «La mayor parte de estas hojas han sido sobres de cartas dirigidas a Jovellanos, y contienen noticias, juicios y hasta chismes, referentes a las personas citadas y a muchas otras que sería largo enumerar». Entre esas noticias, sin referencia alguna, estaba el extracto de esta carta ${ }^{2}$.

El diario proporciona la pista de la fecha del envío de varias cartas desconocidas a Jardine, cuyo contenido reseña en ocasiones. Eliminados los extractos conocidos, el rastreo de fechas de aquellas cartas que sabemos que envió pero cuyo contenido desconocemos permite relacionar este extracto de un 18 de octubre con la anotación de Gijón del viernes 17 de octubre de 1794: «Bella mañana.

1 Biblioteca del Senado, fondo Gómez de Arteche, Reg. 502412, Sig. FH C-295-3.

2 Julio Somoza, «Prólogo», G.M. Jovellanos, Obras completas, tomo VI, Ayuntamiento de Gijón, IFES.XVIII, KRK ediciones, 1994, pág. 61; Inventario de un jovellanista, Madrid, Sucesores de Rivadeneira, 1901, pág. 131. La referencia a Varias hojas... en Inventario, pág. 131, ord. 419. Estas dos cuartillas se conservan junto al Apunte biográfico sobre Campomanes (autógrafo de 13 páginas, Inventario, ord. 417), Muerte del rey Carlos III y primeros días del reinado de Carlos IV (autógrafo de seis páginas, Inventario, ord. 416), Floridablanca (autógrafo de 13 páginas, Inventario, ord. 418c) e Historia de la última enfermedad de Carlos III (autógrafo, ord. 457). El Apunte biográfico sobre Campomanes y Cabarrús y una breve nota de Muerte del rey Carlos III y primeros días del reinado de Carlos IV fueron publicados por el propio Arteche (José GómEZ DE Arteche, Reinado de Carlos IV, en Historia General de España (dirigida por A. Cánovas del Castillo), Madrid, El Progreso Editorial, 1894, t. I, págs. 3-4, 485-488; tomo II, pág. 92, nota 1); el resto, inéditos, se publican en G. M. de Jovellanos, Obras completas, tomo XII, Escritos sobre literatura, ed. de Elena de Lorenzo Álvarez, Ayuntamiento de Gijón, IFES.XVIII, KRK ediciones, 2009, págs. 515-555. 
Trabajo en las Cartas [del viaje de Asturias]. Una larga a Jardine, cuyo extracto se hallará entre las suyas». Caso González lamentaba al constatar su ausencia en la correspondencia: «Alude a ella en el Diario, fecha citada, desgraciadamente sin extractarla» ${ }^{3}$.

Que el extracto se hallaría entre las suyas alude a que guardaba esta correspondencia con vistas a archivarla en la biblioteca del Real Instituto; como le dice a Jardine en mayo de ese mismo año:

Serán conservadas, no sólo para mi provecho, sino para el de mis alumnos. Aun esto último necesita precaución. Pienso aspirar a una licencia para que mi librería pública posea toda especie de libros prohibidos, aunque con separación y con facultad de que sean leídos por los maestros. Basta: tiempo vendrá en que los lea todo el mundo. Si se consigue, allí quedarán las cartas de usted; si no, quedarán en el archivo, y para el fin tanto vale.

Tal correspondencia ha desaparecido, salvo el apunte editado por Nocedal como Borrador a desconocida persona, cuyo receptor y datación aclararon en sucesivos estudios Julio Somoza, Edith Helman y John H. R. Polt, quien señala que es plausible que Jovellanos se hubiera deshecho de ella por temor a la Inquisición. Caso González señalaba que tal correspondencia «o no llegó a formarse nunca, o no pasó a su destino final, o el mismo Jovellanos la destruyó más adelante, cuando corrían tiempos difíciles» 5 .

Así pues, el extracto localizado sería otra muestra de aquella correspondencia perdida de la que sólo se conservaba el citado borrador y varias anotaciones al hilo del diario, al que no las vinculo porque, conservamos el texto del día 18 de octubre de 1794, el apunte es más extenso que los del diario y no se hace en él alusión alguna a ningún otro asunto habitual que mínimamente reseña todos los días, como paseo, lecturas o meteorología ${ }^{6}$.

3 Obras completas, tomo VII, pág. 31, tomo III, pág. 66.

4 Obras completas, tomo II, pág. 634.

5 Julio Somoza, Inventario, pág. 44, que reaccionaba airado contra Nocedal por no haber identificado al destinatario; Edith F. HeLman, «Some consequences of the publication of the Informe de la Ley Agraria by Jovellanos», Estudios hispánicos: Homenaje a Archer M. Huntington, Massachuses, Wellesley College, 1952 , págs. 262-263; John H. R. Potr, «Jovellanos and his English sources», Transactions of the American Philosophical Society, vol. LIV.7 (1964), págs. 12-13 y «Una nota jovellanista: Carta a desconocida persona», Homenaje al profesor Antonio Rodríguez-Moñino, Madrid, Castalia, 1996, tomo II, págs. 81- 86; el borrador de la carta, editado por José Miguel Caso González en Obras completas, tomo II, págs. 634-637, y la consideración de Caso González en pág. 637, nota 4.

6 Compárese con la anotación del diario del sábado, 20 de septiembre de 1794: «Mañana clara; algunas nubes; fresco; el tiempo al vendaval. Correo; larga carta a Jardine: que no espero más humanidad del partido que sucedió a Robespierre; que han mudado de forma y no de espíritu ni máximas en sus procederes; que nada 
Jovellanos y Jardine se habían conocido el 11 de noviembre de 1793; anotaba entonces Jovellanos:

Visita al cónsul inglés, y cita para la mañana siguiente. Estaba en la posada de la Reina. Conversación filosófica sobre la propiedad. Llámase Alejandro Jardine; sirvió en Gibraltar y América, donde perdió el brazo izquierdo en la guerra del 79. [...] Es instruido; viajó por España y Europa; escribió observaciones sobre países y gobiernos, que me ofreció. [...] Es miembro de un club de filósofos, del cual lo fue en otro tiempo Danton. Sus principios son humanos; enemigo de guerra, sangre y violencia; su plan parece inverificable.

Para cuando redacta la carta recuperada, la distancia entre ambos había ido creciendo, como puede constatarse en el conjunto de las anotaciones conservadas $^{8}$; al tiempo que Jardine hablaba con entusiasmo de Godwin y miraba hacia la Francia revolucionaria, Jovellanos le proponía como meta la monarquía parlamentaria inglesa y defendía la «libertad política y civil». El 21 de mayo, en el borrador antes aludido, ya había escrito:

Dirá usted que estos remedios son lentos. Así es, pero no hay otros; y si alguno, no estaré yo por él. Lo he dicho ya: jamás concurriré a sacrificar la generación presente por mejorar las futuras. Usted aprueba el espíritu de rebelión, yo no: le desapruebo abiertamente, y estoy muy lejos de creer que lleve consigo el sello del mérito. Entendámonos. Alabo a los que tienen valor para decir la verdad, a los que se sacrifican por ella; pero no a los que sacrifican otros entes inocentes a sus opiniones, que por lo común no son más que sus deseos personales, buenos o malos. Creo que una nación que se ilustra puede hacer grandes reformas sin sangre, y creo que para ilustrarse tampoco sea necesaria la rebelión. Prescindo de la opinión de Mably que autoriza la guerra civil, sea la que fuere; yo la detesto, y los franceses la harán detestar a todo hombre sensible?.

puede ser peor que la anarquía; que el despotismo sólo puede sostenerse en medio de la ignorancia, pero la anarquía nace de la corrupción, que Izquierdo es uno de los alejados de la corte; que no somos uno por ciento de lo que podríamos. Idea de los canales de riego y navegación a todos los mares. Lectura en gacetas. Por la tarde, al Instituto; lección de dibujo; después a la de lenguas. A paseo. Lectura en Gibbon y en la Historia de Sahagún. Vendaval», Obras completas, tomo VII, págs. 13-14.

Obras completas, tomo VI, pág. 477.

8 Analiza pormenorizadamente lo que de su correspondencia conservamos José Francisco Pérez Berenguel en su edición de las Cartas de España de Jardine de las Letters from Barbary, France, Spain, Portugal \&c. (London, T. Cadell, 1788, 2 vols.; Salamanca, Universidad de Alicante, 2001, 442 págs.).

9 Obras completas, tomo II, pág. 635. 
En cartas posteriores a esta, ya en 1796, escribía: «Carta larga a Jardine, entrando, en fin, en hablar de sus sueños filosóficos; dígole que por última vez, mi poca afición a ellos»; y, finalmente, el 25 de julio de 1796: «Jardine, siempre con sus manías» ${ }^{10}$.

La manía de Jardine esta vez debió de ser una defensa del ateísmo en su vertiente política, asunto nada excepcional, pues la religión venía siendo caballo de batalla en su correspondencia. El 19 de junio de 1794 ya había anotado: «otra de Jardine: no me gustan ya sus ideas políticas, y menos las religiosas; distamos inmensamente en uno y otro»; el 25 de junio: «A Jardine, que no apruebo sus ideas religiosas, ni es posible dejar de reconocer las que predica la naturaleza y abarca tan agradablemente la razón ${ }^{11}$.

Jovellanos, en el marco de la ilustración liberal o el liberalismo doctrinario que en buena medida él mismo ayuda a conformar ${ }^{12}$, responde tanto a los conceptos como a los métodos: defiende la libertad y necesidad de que los filósofos combatan la superstición de la religión mediante la razón y rechaza la imposición violenta del dogma político. Como en este caso se trata del ateísmo jacobino, invoca el orden de la naturaleza como demostración de la existencia divina, apartándose de la actitud fideística y reclamando una razón que alcanza a vislumbrar un orden y unidad del cosmos bajo la aparente diversidad de los seres, que exigen la existencia de un creador — aquellas ideas religiosas que «predica la naturaleza y abarca tan agradablemente la razón»—; y concluye con una defensa de la ley entendida como pacto político necesario, que una vez acordado ha se ser defendido por la fuerza pública, lo que le lleva a condenar, una vez más, los acontecimientos de la Francia revolucionaria.

Escrita en la etapa en que guillotinado Robespierre, los jacobinos son perseguidos por los termidorianos con una violencia digna de la llamada «época del Terror», pero discutiendo aún sobre las propuestas jacobinas, el diálogo entre la respuesta de Jovellanos y lo que leemos entre líneas que le proponía Jardine muestra la tensión reforma / revolución que se acentúa a finales del siglo XVIII, cuyos polos ajustadamente encarnan Jovellanos y Jardine, pues ambos comparten - en un principio- los fines, pero no los medios, y que concluiría con el desmantelamiento del Antiguo Régimen.

Éste es el contexto del extracto recuperado de la carta, escrita en Gijón el 18 de octubre de 1794. Como en muchas otras, manifiesta el carácter confiden-

10 Obras completas, tomo III, págs. 230-356.

11 Obras completas, tomo VI, págs. 594 y 597.

12 Luis Díez del Corral, El liberalismo doctrinario, Instituto de Estudios Políticos, Madrid, 1945; Antonio Elorza, La ideología liberal en la Ilustración española, Tecnos, Madrid, 1970, págs. 97 y ss.; Ignacio FERnández Sarasola, «Introducción», Obras completas, tomo XI, Escritos políticos, pág. XLI. 
cial y franco propio de su correspondencia privada; como en pocas, se expresa sobre principios políticos con claridad meridiana: en el diálogo con el cónsul, el entusiasmo con que éste expone ideas de que Jovellanos disiente le obliga a replicar y exponer abiertamente sus puntos de vista, tanto que el 24 de mayo de 1794 escribe: «A Jardine, prevenciones sobre nuestra correspondencia; que no se puede tratar de todo; que sólo privada y confidencial[mente] se deben exponer libremente las ideas» ${ }^{13}$.

18 de octubre ${ }^{14}$. A Jardin ${ }^{15}$. Que no puedo concebir justicia sin ley, ni ley sin autor, ni verdad sin justicia, ley y supremo autor. Que en este sentido serán objetos a que deben dirigirse en su perfectibilidad la razón pública y privada. De ellas pende el orden, de ellas la felicidad. Ambos se deben a su autor. Suponen y exigen una religión. En este p[un]to es neces[ari]a la libertad. Aún toca al filósofo combatir la superstición en todas y aun en la suya; sólo con el raciocinio, sin violenc[ia] ni persecuc[ió]n. Temeridad de los jacobinos en este punto. Sacrílega locura en querer erigir el ateísmo en dogma político. Que la raz[ó]n no fue dada al h[ombr]e p[ar]a envilecerle y embrutecerle. Que no se le ha dado idea de un estado más feliz sólo $\mathrm{p}[\mathrm{ar}] \mathrm{a}$ conocer que es incapaz de alcanzarle. Triste del que no tiene este consuelo, más del que lo renuncia. Que en n[ues]tra fe tiene gran $\mathrm{p}$ [ar]te el sentim[ien]to [con] que vemos el orden del universo y sentimos la intelig[enci]a y la bondad de su autor.

Que él quiere que la fuerza ayude a la opinión, yo no. Todo gobierno es bueno, siempre que la nación nombre, dirija y castigue a los deposit[ari]os de la autoridad que les entrega, donde reinan la igualdad civil, el orden, la seguridad y la paz. Que no concibo cómo sin gobierno, sin leyes, pueda la raz[ó]n gobernar al hombre, cómo dejar de tener pasiones o de seguirlas. Ejemplo en dos movidos de un mismo deseo, inspirados en una misma necesidad ¿será la fuerza q[uié]n decida? De a[h]í la guerra social, el hombre no será social sino animal gregario. Ning[un]a fuerza, sino la de opinión; cuando esta haya establecido sus leyes, una fuerza pública contra los refractarios ${ }^{16}$. Juicio por este principio de la conducta de los franceses: buena en el principio, detestable en el progreso de la revoluc[ió]n.

\footnotetext{
13 Obras completas, tomo VI, pág. 584.

14 Ms.: $8^{r e}$.

15 No se conservaba ningún autógrafo en que Jovellanos mencionara al cónsul, y reflexionaba Caso González: «Es posible que Jovellanos escribiera mal el nombre, al menos en un principio, porque Nocedal transcribe Jardings y Somoza Jardines que considera, sin razón, forma castellanizada de Hardings. Sin embargo, Jardine es la forma que figura en el expediente. En adelante lo transcribiré siempre así, sin anotar la variante», tomo VI, pág. 477, nota 2. Como se ve, Jovellanos escribía Jardin.

16 Ms.: refactrarios.
} 


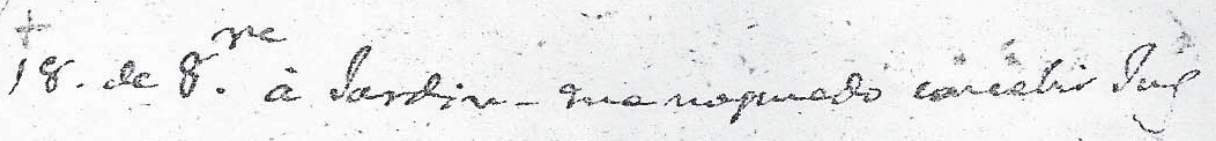

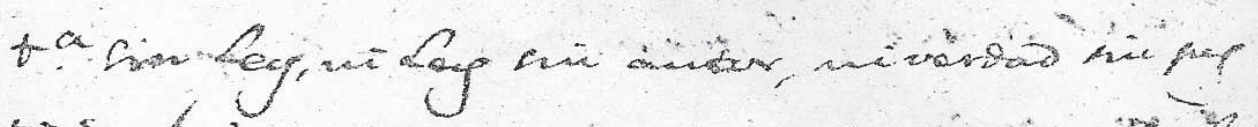

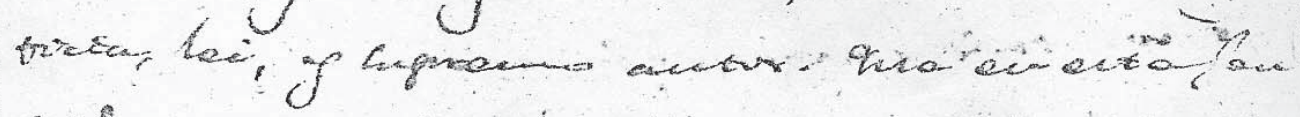

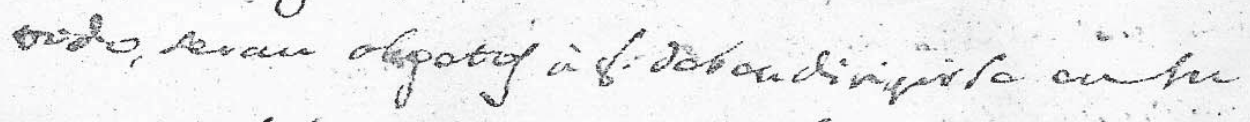

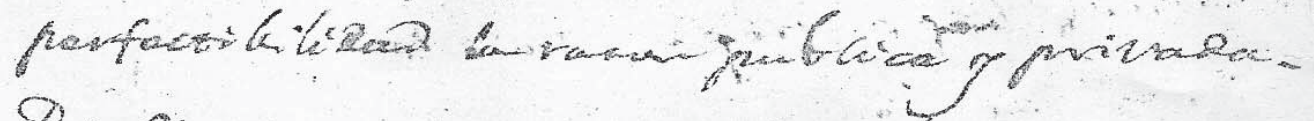

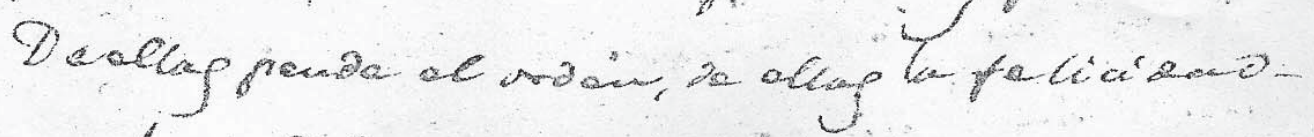

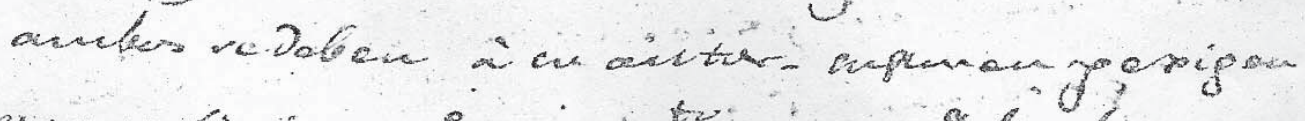

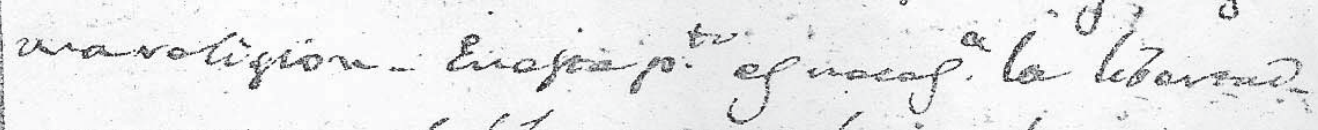

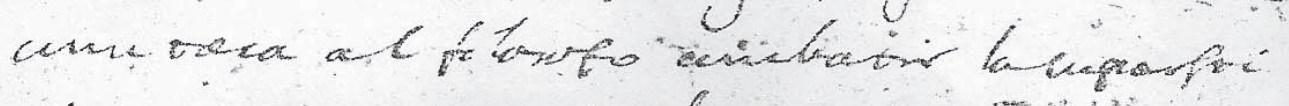

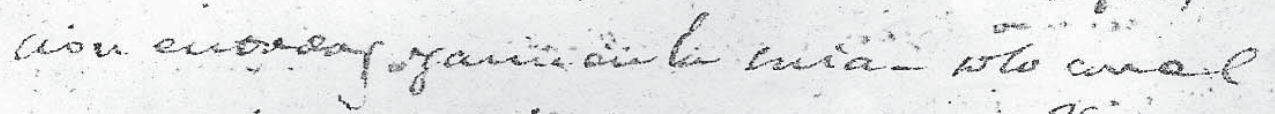

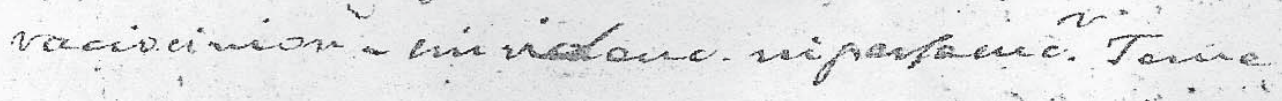

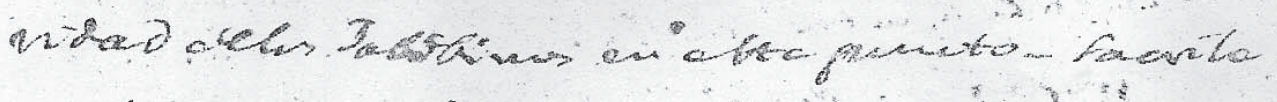

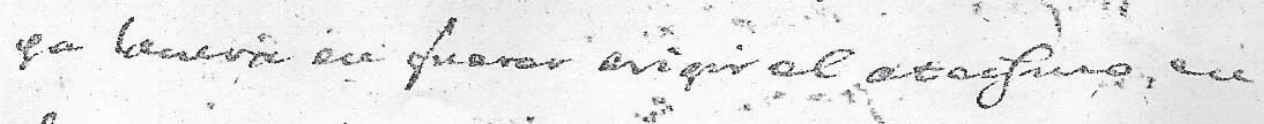

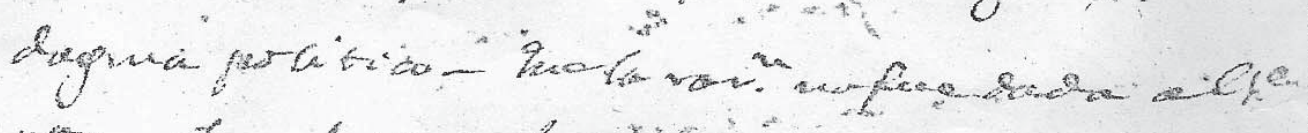

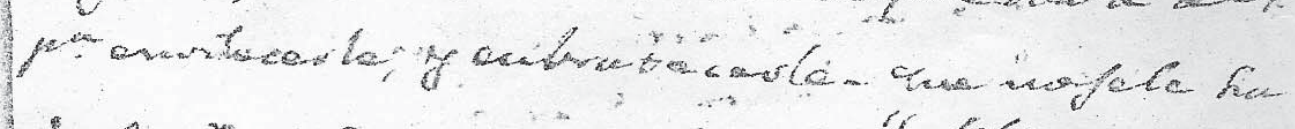

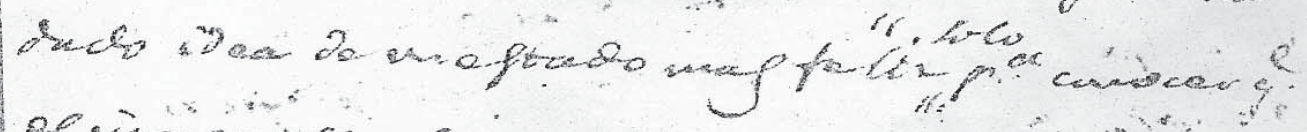

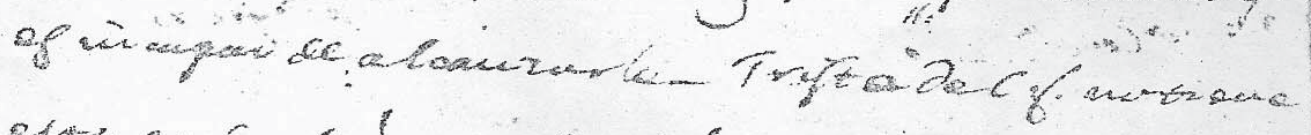

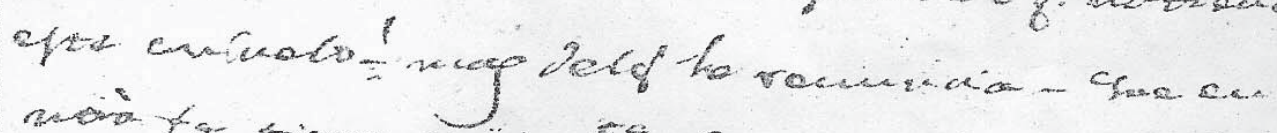

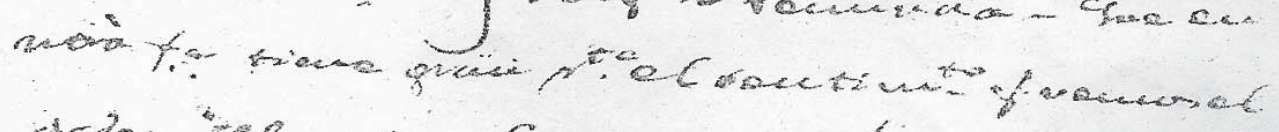

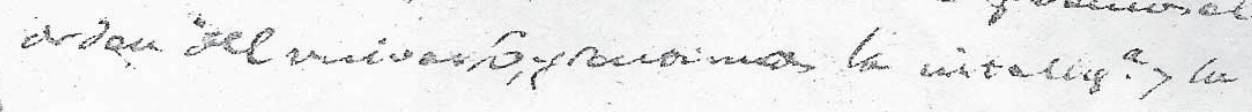

$-30-$ 


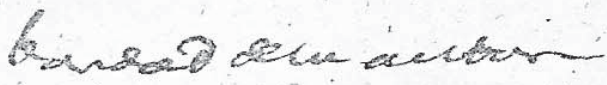

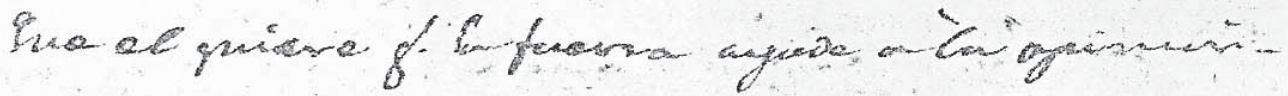

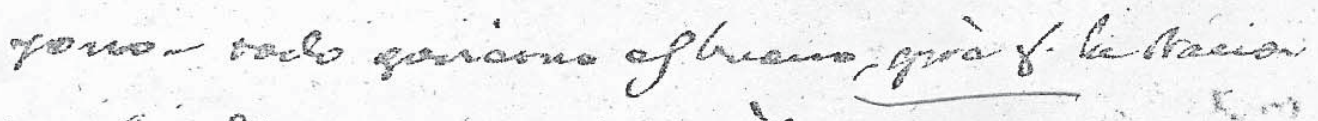

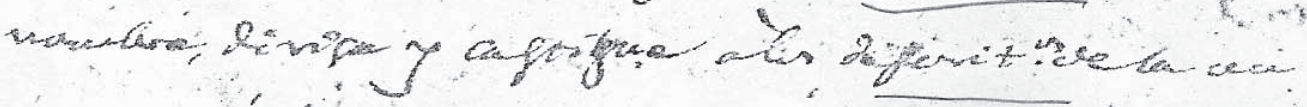

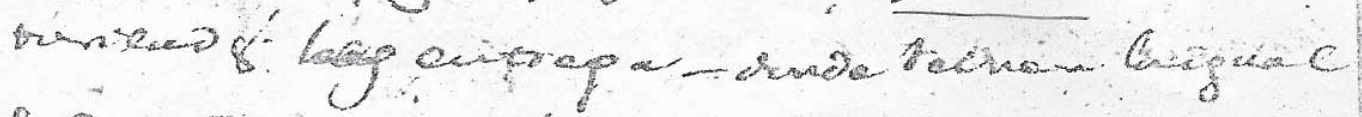

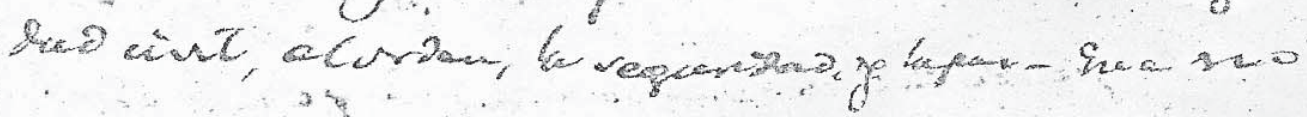

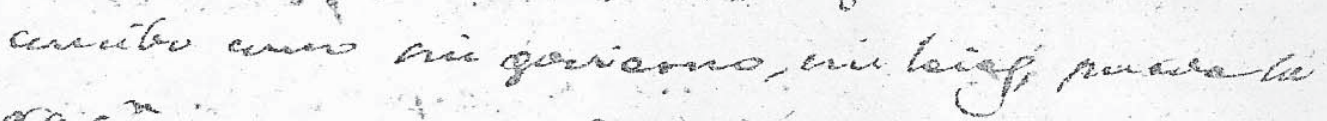

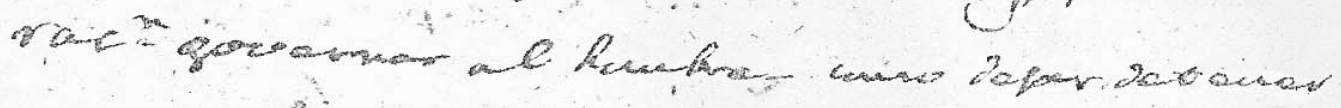

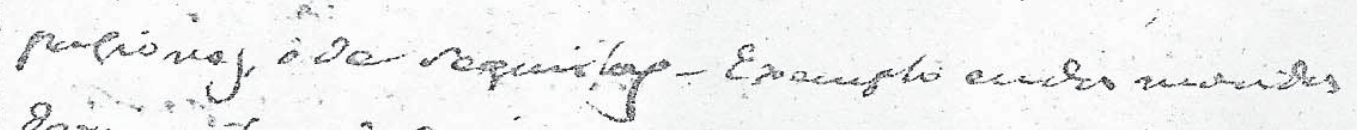

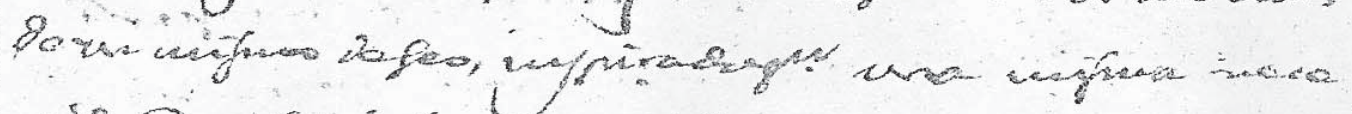

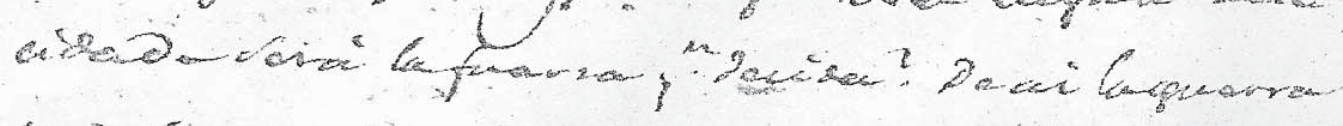

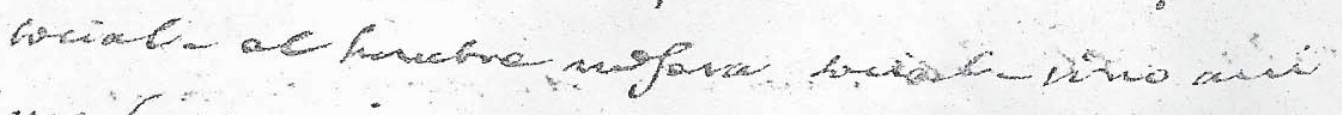

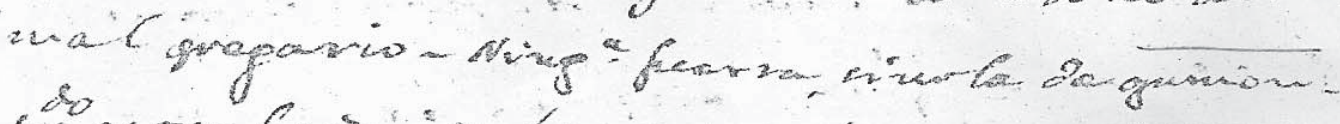

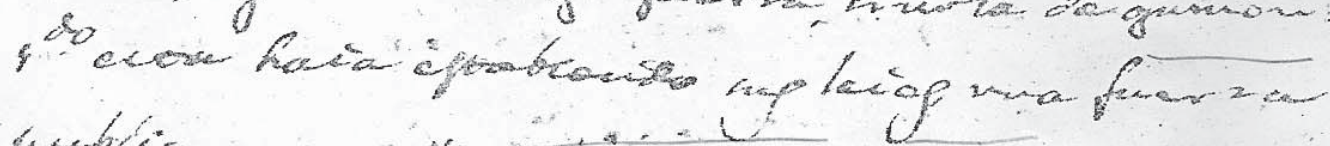

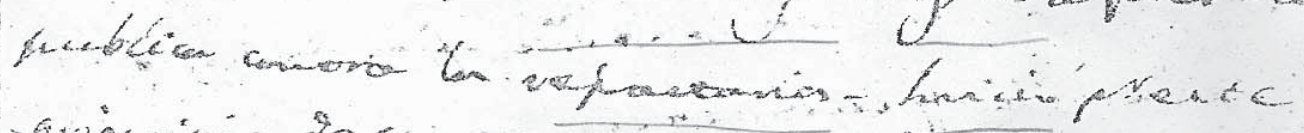

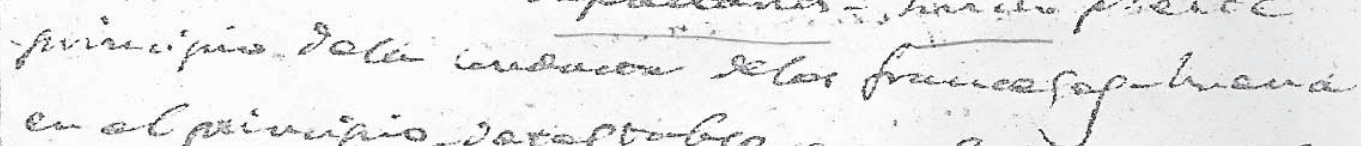

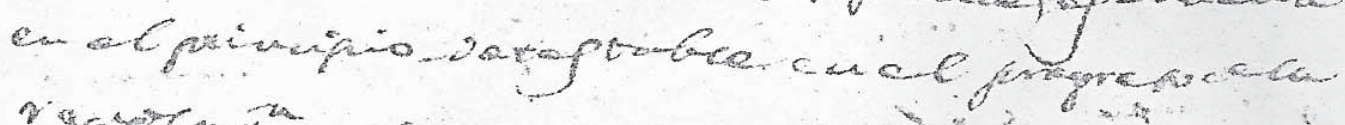

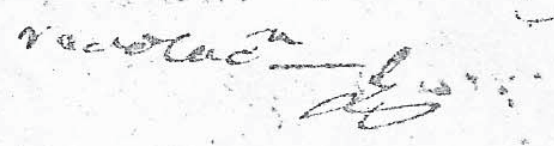

$-31-$ 